\title{
UNILATERAL MICROCORNEA AND ENOPHTHALMOS WITH BILATERAL ANTERIOR AND POSTERIOR ANOMALIES* ${ }^{\dagger}$
}

\author{
BY \\ D. V. BATRA AND S. D. PAUL \\ Department of Ophthalmology, Institute of Postgraduate Medical Education and Research, \\ Chandigarh, India
}

THE term microcornea should be reserved for the condition wherein an abnormally small cornea (diameter less than $11 \mathrm{~mm}$.) occurs in an otherwise relatively normal eye (Mann, 1957). Friede (1922) suggested the term "anterior microphthalmos", because the whole of the anterior segment of the eye seems to be small. The rectus muscles are inserted abnormally far forwards, and the corneal curvature tends to be increased so that the corneal refraction is relatively great and the eye tends to be myopic. The total refraction may be almost emmetropic (Mann, 1957). Vision is usually unaffected, but the condition may occur coincidentally with buphthalmos (François and Neetens, 1955); or buphthalmos may be present in the other eye (Srivastava, 1961). In some cases it is difficult to distinguish between anterior microcornea and microphthalmos. Associated ocular anomalies include colobomata, persistent pupillary membrane, mesoblastic tissue in the angle of the anterior chamber, microphakia, congenital cataract, microblepharon, and smallness of the orbit and extra-ocular muscles.

Friedman and Wright (1952) reported a pedigree with eight cases among 37 individuals in five generations; Martin (1888) and Gatterbauer (1943) found it in three generations of one family; Friede (1922), Peter (1924), and Sommers (1949) suggested an occasional recessive transmission.

The case here presented shows a combination of anterior and posterior segmental anomalies of congenital origin, with unilateral enophthalmos on the same side as the microcornea.

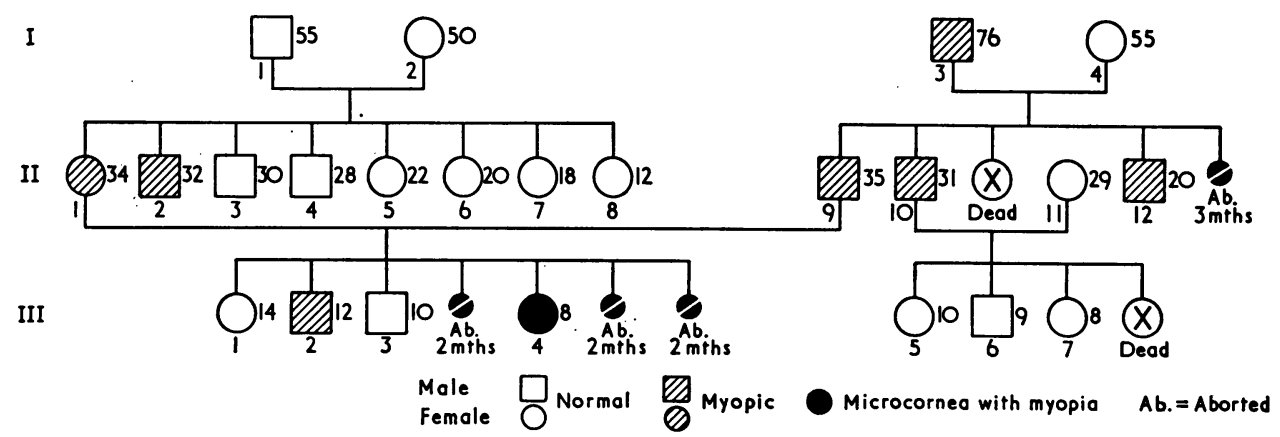

Fig. 1.-Family tree.

* Received for publication January 10, 1966.

† Address for reprints: Civil Hospital, Nabha District, Patiala, Punjab, India. 


\section{Case Report}

The propositus (III,4), a Hindu girl aged about 8 years, was brought to the clinic because of poor vision from early childhood. Her general health and intelligence were normal.

Pedigree.-The family tree shows many cases of myopia over three generations (Fig. 1).

I, 3. Paternal grandfather, aged 76 . $-6 \mathrm{D}$ sph., both eyes.

II, 9. Father, aged 35. -9 D sph., both eyes. There were myopic temporal crescents and tesselated fundi.

II,10. Father's brother, aged 31. -3.5 D sph., both eyes.

II,12. Father's brother, aged 20. - $3 \mathrm{D}$ sph., both eyes.

II, 1. Mother, aged 34. Visual acuity $6 / 24$, improved to $6 / 6$ with $-1 \mathrm{D}$ sph., $-0.5 \mathrm{D}$ cyl., axis $180^{\circ}$, both eyes.

II, 2. Mother's brother, aged 32. -4 D sph., both eyes.

III, 2. Elder brother, aged 12. $-5 \mathrm{D}$ sph., both eyes.

III, 3. Elder brother, aged 10. $-0.5 \mathrm{D}$ sph., both eyes.

Examination.-Visual acuity was $6 / 60$ in the right eye, improved to $6 / 24$ with $-6 \mathrm{D}$ sph., -3 D cyl., axis $90^{\circ}$. The acuity in the left eye was finger counting at 1 metre not improved with glasses.

The right eye showed narrowing of the palpebral aperture (Fig. 2); the cornea was small, and the anterior chamber of normal depth. An iris coloboma was situated downwards and slightly inwards.

The left eye showed horizontal nystagmus and a convergent squint. The cornea and the depth of the anterior chamber were normal. The pupil was displaced downwards with an iris coloboma at 6 o'clock (Fig. 3). There was no restriction of ocular movements.

The left eye showed horizontal nystagmus with convergent squint with normal cornea and anterior chamber depth. The pupil was displaced downwards with an iris coloboma at 6 o'clock. (Fig. 3). There was no restriction of ocular movements.

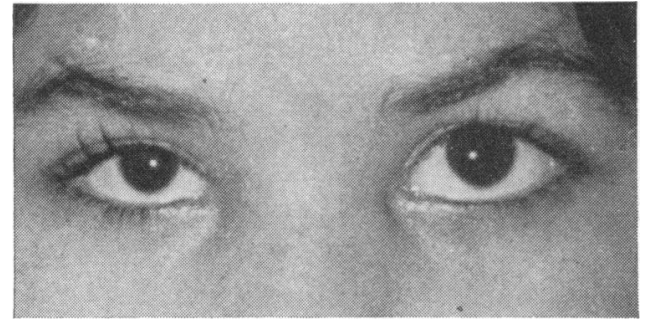

FIG. 2.-Unilateral microcornea with enophthalmos.

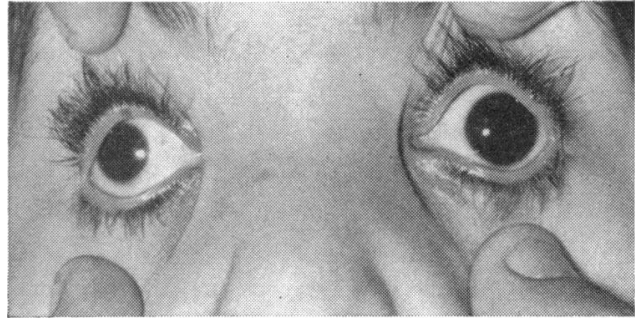

FIG. 3.-Bilateral iris colobomata.

OCUlar Tension: digitally normal in both eyes.

CORneal Diameter: Right: vertical $9 \mathrm{~mm}$., horizontal $9 \mathrm{~mm}$. Left: vertical $11.5 \mathrm{~mm}$., horizontal $11.0 \mathrm{~mm}$.

OrBit: Both eyes, $33 \mathrm{~mm}$. wide $\times 28 \mathrm{~mm}$. high.

ORBITAL INDEX: Both eyes, 84.9.

OPHTHALMOMETER: Right: vertical $38 \cdot 2$ dioptres, horizontal $38 \cdot 2$ dioptres.

Left: vertical 37.8 dioptres, horizontal $38 \cdot 2$ dioptres.

Corneal Radius of CuRvature: Right: vertical and horizontal $8.7 \mathrm{~mm}$.

Left: vertical $8.8 \mathrm{~mm}$., and horizontal $8.7 \mathrm{~mm}$.

ExopHTHALmos: Right: $12 \mathrm{~mm} .$, left: $16 \mathrm{~mm}$.

FuNDUs: Both eyes showed coloboma of the choroid and myopic degenerative changes, with vitreous floaters in both eyes, more on the right (Fig. 4, opposite).

SkULL: Transverse (biparietal) 6.25 in.; antero-posterior (fronto-occipital) 11.0 in.; circumference, $19 \cdot 25$ in.

\section{Discussion}

According to François and Neetens (1955), retardation or aberration of the growth of the ectoderm of the optic cup is linked with the shape and dimensions of the rim 
FIG. 4.-Coloboma of the choroid.

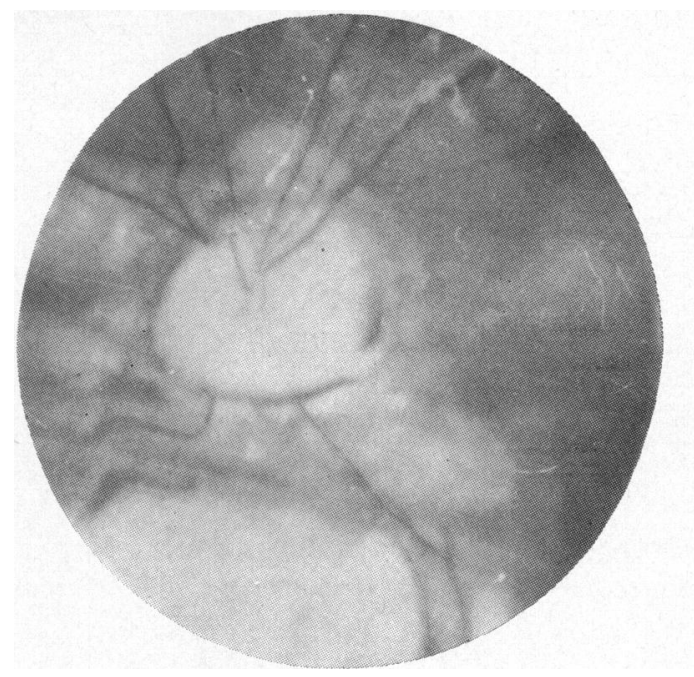

of the cup early in its development at the $12 \mathrm{~mm}$. stage; Mann (1957) considered that it occurred after the fifth month, when the eye had become spherical but before the growth of its anterior segment was complete.

Enophthalmos is an unusual anomaly, and we could find no instance of anterior microphthalmos associated with enophthalmos in the literature. The recession of the eyeball may be due to a deficiency in the retro-ocular pad of fat or to laxness of the suspensory apparatus with forward insertion of the extra-ocular muscles in an eye with anterior microphthalmos.

\section{Summary}

A case is presented of unilateral microcornea with enophthalmos, and bilateral colobomata of the iris and choroid. There were many cases of myopia in the patient's family.

\section{REFERENCES}

François, J., and Neetens, A. (1955). Acta genet. med. (Roma), 4, 217.

Friede, R. (1921). Klin. Mbl. Augenheilk., 67, 192. (1922). Ibid., 69, 561.

Friedman, M. W., and Wright, E. S. (1952). Amer. J. Ophthal., 35, 1017.

Gatterbauer, J. (1943). Klin. Mbl. Augenheilk., 109, 813.

MANN, I. (1957). "Developmental Abnormalities of the Eye", 2nd. ed., p. 353. B.M.A., London.

Martin, F. (1888). "Über Microphthalmus" (Thesis). Erlangen.

Peter, R. (1924). v. Graefes Arch. Ophthal., 115, 29.

Sommers, I. G. (1949). "Histology and Histopathology of the Eye and its Adnexa". Grune and Stratton, New York.

Srivastava, S. P. (1961). Brit. J. Ophthal., 45, 382. 